\section{Angiotensin II type 1 receptor blockade partially attenuates hypoxia-induced pulmonary hypertension in newborn piglets: relationship with the nitrergic system}

J.S. Camelo Jr., A.R. Martins, E. Rosa, S.G. Ramos, D. Hehre, E. Bancalari and C. Suguihara

The Brazilian Journal of Medical and Biological Research is partially financed by
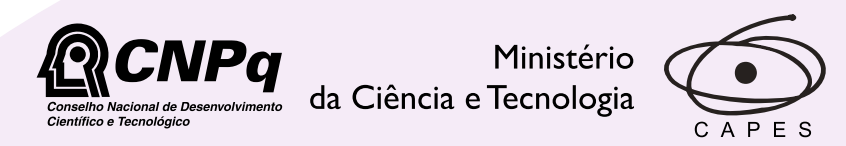

Ministério da Educação

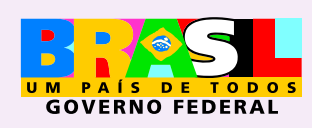

Institutional S ponsors
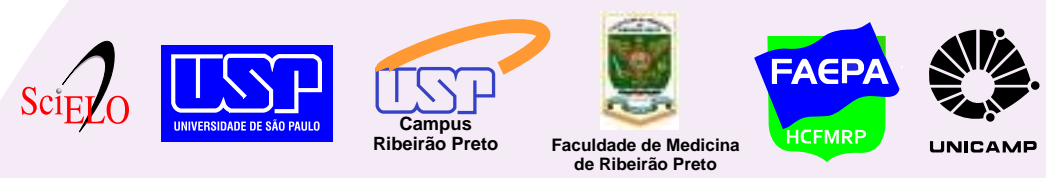

$\oplus$ SHIMADZU

UNICAMP
1디맘

Associaçăo
Fundo de Incentivo

plore High - Performance MS Orbitrap Technology analitica Thermo 


\title{
Angiotensin II type 1 receptor blockade partially attenuates hypoxia-induced pulmonary hypertension in newborn piglets: relationship with the nitrergic system
}

\author{
J.S. Camelo Jr. ${ }^{1}$, A.R. Martins ${ }^{2,3}$, E. Rosa ${ }^{2}$, S.G. Ramos ${ }^{4}$, D. Hehre ${ }^{5}$, \\ E. Bancalari ${ }^{5}$ and C. Suguihara ${ }^{5}$ \\ ${ }^{1}$ Departamento de Puericultura e Pediatria, Faculdade de Medicina de Ribeirão Preto, \\ Universidade de São Paulo, Ribeirão Preto, SP, Brasil \\ ${ }^{2}$ Departamento de Farmacologia, Faculdade de Medicina de Ribeirão Preto, \\ Universidade de São Paulo, Ribeirão Preto, SP, Brasil \\ 3 Instituto de Ciências Biológicas, Universidade Federal do Triângulo Mineiro, Uberaba, MG, Brasil \\ ${ }^{4}$ Departamento de Patologia, Faculdade de Medicina de Ribeirão Preto, Universidade de São Paulo, \\ Ribeirão Preto, SP, Brasil \\ ${ }^{5}$ Department of Pediatrics, Division of Neonatology, Neonatal Developmental Biology Laboratory, \\ University of Miami Miller School of Medicine, Miami, FL, USA
}

\begin{abstract}
The objective of this study was to observe possible interactions between the renin-angiotensin and nitrergic systems in chronic hypoxia-induced pulmonary hypertension in newborn piglets. Thirteen chronically instrumented newborn piglets $(6.3 \pm 0.9$ days; $2369 \pm 491 \mathrm{~g}$ ) were randomly assigned to receive saline (placebo, $P$ ) or the $A T_{1}$ receptor $\left(A T_{1}-R\right)$ blocker $L-158,809(L)$ during 6 days of hypoxia $\left(\mathrm{FiO}_{2}=0.12\right)$. During hypoxia, pulmonary arterial pressure $(\mathrm{Ppa} ; \mathrm{P}<0.0001)$, pulmonary vascular resistance (PVR; $P<0.02$ ) and the pulmonary to systemic vascular resistance ratio (PVR/SVR; $P<0.05)$ were significantly attenuated in the $L(N=7)$ group compared to the $P$ group $(N=6)$. Western blot analysis of lung proteins showed a significant decrease of endothelial NOS (eNOS) in both $\mathrm{P}$ and $\mathrm{L}$ animals, and of $A T_{1}-\mathrm{R}$ in $\mathrm{P}$ animals during hypoxia compared to normoxic animals (C group, $N=5 ; P<0.01$ for all groups). $A T_{1}-R$ tended to decrease in $L$ animals. Inducible NOS (iNOS) did not differ among $P, L$, and $\mathrm{C}$ animals and iNOS immunohistochemical staining in macrophages was significantly more intense in $L$ than in $P$ animals $(P<0.01)$. The vascular endothelium showed moderate or strong eNOS and $A T_{1}-R$ staining. Macrophages and pneumocytes showed moderate or strong iNOS and $A T_{1}-R$ staining, but $C$ animals showed weak iNOS and $A T_{1}-R$ staining. Macrophages of $L$ and $P$ animals showed moderate and weak $A T_{2}-R$ staining, respectively, but the endothelium of all groups only showed weak staining. In conclusion, pulmonary hypertension induced by chronic hypoxia in newborn piglets is partially attenuated by $A T_{1}-\mathrm{R}$ blockade. We suggest that $A T_{1}-\mathrm{R}$ blockade might act through $A T_{2}-\mathrm{R}$ and/or Mas receptors and the nitrergic system in the lungs of hypoxemic newborn piglets.
\end{abstract}

Key words: Newborn animals; Pulmonary hypertension; Angiotensin II; Angiotensin receptors; Hypoxia

\section{Introduction}

Pulmonary hypertension induced by chronic hypoxia is a complex process of sustained elevation of pulmonary artery pressure involving vasoconstriction and pulmonary vessel remodeling. These events have been consistently observed in experimental animal models and in adult humans (1), but in newborns and in neonatal animal models, only one study showed involvement of the renin-angiotensin system (RAS) (2). They are multifactorial processes involving different mediators such as endothelin and angiotensin II (Ang II) and nitric oxide. Ang II is a powerful pulmonary vasoconstrictor and promoter of vascular smooth muscle cell (VSMC) growth in humans and animals. Ang II can act through the

Correspondence: J.S. Camelo Jr., Departamento de Puericultura e Pediatria, HC, FMRP, USP, Av. Bandeirantes, 3900, 14049-900 Ribeirão Preto, SP, Brasil. Fax: +55-16-3602-2700. E-mail: jscamelo@fmrp.usp.br

Received August 22, 2011. Accepted January 19, 2012. Available online February 10, 2012. Published February 17, 2012. 
angiotensin type 1 receptor $\left(A T_{1}-R\right)$ to induce mitogenesis, stimulate DNA synthesis, promote cellular proliferation in cultured rat VSMC, and to enhance growth factors such as platelet-derived growth factor and transforming-growth factor $\beta$ (3-5). The mechanisms of action of Ang II involve binding to $A T_{1}-R$, as demonstrated in different studies reporting attenuation of pulmonary hypertension by $A T_{1}-R$ blockers and transient up-regulation of $A T_{1}-R$ in adult rats exposed to chronic hypoxia $(6,7)$. Moreover, we have demonstrated that pulmonary vasoconstriction induced by acute hypoxia was significantly attenuated by the $A T_{1}-R$ blocker losartan in piglets (2). Therefore, it is possible that the RAS participates in the mechanisms leading to pulmonary hypertension induced by chronic hypoxia $(4,5)$.

It is well known that $A T_{1}-\mathrm{R}$ blockade stimulates nitric oxide (NO) production via $A T_{2}-R$, a process that may result in the attenuation of pulmonary hypertension induced by chronic hypoxia $(8,9)$. One possible endothelial mechanism of regulation of the pulmonary vascular tone during chronic hypoxia is by decreasing endothelial NO synthase (eNOS) expression, a hypothesis supported by the fact that eNOS expression is significantly lower in newborn piglets exposed to chronic hypoxia compared to a control group (10). However, the interactions between the RAS and nitrergic systems in the pulmonary vasculature have not been studied in human or animal newborns with pulmonary hypertension induced by chronic hypoxia. Asphyxiated newborn infants are predisposed to persistent pulmonary hypertension, and these mechanisms could be partially involved in this condition (11).

We propose, as a working hypothesis, that pulmonary hypertension induced by chronic hypoxia in newborn piglets is mediated by increased circulating Ang II levels, associated with down-regulation of eNOS. As a consequence, hypoxic pulmonary hypertension can be ameliorated by pretreatment with the $A T_{1}-\mathrm{R}$ blocker $\mathrm{L}-158,809$ through increased NO production.

\section{Material and Methods}

\section{Animal preparation}

Thirteen newborn piglets (age $=6.3 \pm 0.9$ days; weight $=$ $2369 \pm 491 \mathrm{~g}$ ) were anesthetized intraperitoneally (ip), with $2 \%(\mathrm{w} / \mathrm{v})$ isoflurane and $50 \mu \mathrm{g} / \mathrm{kg}$ fentanyl. The piglets were paralyzed with an ip injection of $0.4 \mathrm{mg} / \mathrm{kg}$ pancuronium bromide. A 3.5-mm tube was placed in the trachea and the piglet was mechanically ventilated with a time-cycled, pressure-limited infant ventilator (Sechrist, Model IV-100 B Infant Ventilator, USA) with peak inspiratory pressure set at $12 \mathrm{cmH}_{2} \mathrm{O}$, positive end-expiratory pressure set at $2 \mathrm{cmH}_{2} \mathrm{O}$, with a respiratory rate of $30 \mathrm{breaths} / \mathrm{min}$, an inspiratory time of $0.5 \mathrm{~s}$, and $\mathrm{FiO}_{2}=0.50$ during surgery. The femoral artery was cannulated with a 3.5-French umbilical catheter and the femoral vein with a 5-French Swan-Ganz thermodilution catheter. The Swan-Ganz catheter was advanced under fluoroscopic guidance into the pulmonary artery, and was maintained patent with a heparin lock $(1000 \mathrm{U} / \mathrm{mL})$. Both catheters were fixed in a pouch located on the back of the animal. The piglets received cefoxitin intravenously at 100 $\mathrm{mg} \cdot \mathrm{kg}^{-1} \cdot \mathrm{day}^{-1}$ and acetaminophen (10 mg/kg orally) immediately after surgery and thereafter as needed.

The femoral artery catheter was used for mean systemic arterial pressure (Psa) measurements and for blood sampling for the determination of arterial blood gases (ABG), $\mathrm{pH}$, and hemoglobin. The Swan-Ganz catheter was used to measure pulmonary artery (Ppa) and wedge pressure (Pwp), right atrial pressure (Rap), and cardiac output (CO). $\mathrm{CO}$ was measured by thermodilution using a $\mathrm{CO}$ computer (Model 95510-1, Edwards Laboratory, USA). Vascular pressures (Ppa, Pwp, Rap, Psa) were measured with pressure transducers (Model P23-ID, Gould Instruments, USA) and Grass pre-amplifiers (Model 7D, Grass Instrument, USA). All signals were simultaneously digitized with a frequency of $100 \mathrm{~Hz}$ using an analog-to-digital board (AT - CODAS, Dataq Instruments Inc., USA) and stored in a personal computer for analysis. $\mathrm{ABG}$ and $\mathrm{pH}$ were analyzed with a blood gas analyzer (model 238, Ciba-Corning, England) and corrected for core temperature. Hemoglobin was measured with a CO-oximeter (model 482 - Instrumentation Laboratory, USA).

\section{Study protocol}

The studies were started 48-72 h after surgery. Thirteen unanesthetized and chronically instrumented newborn piglets were randomly assigned to receive saline as placebo $(P$ group; $N=6$ ), or the $A T_{1}-R$ antagonist $L-158,809$ ( $L$ group; $\mathrm{N}=7$ ). The animals were placed in a sling inside a Plexiglas chamber, in a thermoneutral environment $\left(26^{\circ}-28^{\circ} \mathrm{C}\right)$ with $70 \%$ relative humidity, where $\mathrm{CO}_{2}$ was scavenged with soda lime, and the $\mathrm{CO}_{2}$ tension was kept at less than $6 \mathrm{mmHg}$. Piglets were fed ad libitum with newborn piglet milk during the study. All hemodynamic measurements were made during quiet sleep and evaluated by behavioral assessment. Heparinized saline was infused continuously through the pulmonary artery catheter $(10 \mathrm{IU} / \mathrm{mL})$ at a rate of $5 \mathrm{~mL} / \mathrm{h}$ throughout the study.

After a 30-min period of stabilization, the hemodynamic measurements (Psa, Ppa, Pwp, Rap, CO), and blood sampling for $A B G$ were obtained and referred to as baseline normoxia values. Saline or L-158,809 $\left(1 \mathrm{mg} \cdot \mathrm{kg}^{-1} \cdot \mathrm{day}^{-1}\right.$, ip) was administered to the animals immediately after the measurements. The potassium salt of $L-158,809$ was prepared at $3 \mathrm{mg} / \mathrm{mL}$ in $15 \%(\mathrm{w} / \mathrm{v})$ saturated sodium bicarbonate solution and the dose was selected on the basis of a study performed in adult pigs (12). After obtaining the baseline values, the oxygen concentration was reduced to $12 \%$ and kept at this level for 6 days, allowing free movement of the animals. The hemodynamic measurements and blood sampling were repeated twice on the second and sixth days of continuous hypoxia. Systemic vascular (SVR) and 
pulmonary vascular (PVR) resistances were calculated from the hemodynamic data. Five healthy newborn piglets were used as controls for immunohistochemistry and for immunoblotting studies (C group).

Handling and care of the animals were in accordance with the guidelines of the National Institute of Health, and the study protocol was approved by the Animal Care and Use Committee of the University of Miami.

\section{Pathology and immunohistochemistry}

Piglets were sacrificed with Euthanasia ${ }^{\circledR}$ solution immediately after completion of the experiment and the lungs were removed en bloc from the thorax. One lung was inflated through the trachea with $4 \%(\mathrm{w} / \mathrm{v})$ paraformaldehyde in 0.1 $\mathrm{M}$ sodium phosphate buffer, $\mathrm{pH} 7.4$, at room temperature, using a column pressure of $20 \mathrm{cmH}_{2} \mathrm{O}$ for $30 \mathrm{~min}$, and was then immersion-fixed in the same solution for at least 1 week. The other lung was processed for paraffin embedding.

The fixed lung was dehydrated, cleared with xylene and paraffin-embedded. Five-micrometer sections were cut, mounted on gelatin-chromalum-coated glass slides, and used for immunohistochemistry. All sections from groups $C$, $P$, and $L$ were immunostained simultaneously for each of the primary antibodies used. Antigen recovery from dewaxed lung sections was carried out using a microwave oven, and immunostaining was performed as described elsewhere $(13,14)$. Sections were then incubated with rabbit anti$\mathrm{AT}_{1}-\mathrm{R}$ (Santa Cruz Biotechnology Inc., USA), goat anti-AT 2 (Santa Cruz Biotechnology), mouse anti-eNOS (clone 3, BD Transduction Laboratories, USA), mouse anti-iNOS (clone 6, BD Transduction Laboratories), or rabbit anti-smooth muscle anti- $\alpha$-actin (RDI Inc., USA) antibodies. Controls were prepared by incubating sections overnight with anti$A T_{1}-R$ or anti-AT $2-R$ antibodies previously adsorbed with their respective immunogens at 1:10 (w/v) and 1:5 (w/v) in blocking buffer, respectively. Primary antibodies replaced blocking buffer in additional controls. Antibodies were detected with a secondary biotinylated antibody and the Elite ABC kit (Vector, USA), using 3,3'-diaminobenzidine (Pierce Biotechnology Inc., USA) as the chromogen. Sections were analyzed and photographed with a model BX60-F3 microscope, a PM-35DX camera and a PM30 exposure control module (Olympus, Japan). Images were digitized using a Sprintscan 35 Plus Polaroid, and plates were mounted using the Photoshop 7.0 software.

Immunohistochemically stained sections were evaluated and scored blindly and independently by two investigators (ARM, SGR). A numerical value (modal score) ranging from 0 to 3 was assigned by each investigator to each slide on the basis of intensity and distribution of the stain, for the following variables: arterial and venular endothelium, capillaries, macrophages, alveolar interstitium, alveolar cells (type I and II pneumocytes), and bronchial epithelium. A zero score was assigned if no stain was present, grade 1 was assigned if there was mild staining, grade 2 if there was moderate staining, and grade 3 if staining was strong $(15,16)$.

\section{Western blotting analysis}

Frozen lungs were homogenized (1 $\mathrm{g}$ lung to $9 \mathrm{~mL}$ buffer) in a water-ice bath, in $20 \mathrm{mM}$ Tris- $\mathrm{HCl}$ buffer, $\mathrm{pH} 7.4$, containing $0.32 \mathrm{M}$ sucrose, $1 \%(\mathrm{w} / \mathrm{v})$ sodium dodecyl sulfate (SDS), $10 \mathrm{mM}$ disodium ethylenediamine tetra-acetic acid, $1 \mathrm{mM}$ benzamidine, $0.3 \mathrm{mM}$ phenylmethanesulfonylfluoride, $0.3 \mu \mathrm{M}$ aprotinine, and $2 \mathrm{mM} \beta$-mercaptoethanol, using a Potter-Elvehjem homogenizer (Glas-Col, USA) at 1000 rpm. Homogenates were subjected to SDS-PAGE in $7-20 \%$ gradient gels using a discontinuous system (17). Proteins on the gel were transferred to nitrocellulose membranes (Hybond ECL, Amersham Biosciences, England) (18), which were used for the immunodetection of eNOS, inducible NOS (iNOS) and $A T_{1}-\mathrm{R}$, using the same primary antibodies as those employed for immunohistochemistry. Immunoblots were developed and documented using an enhanced chemiluminescence kit (Amersham Biosciences) and Hyperfilm ECL (Amersham Biosciences), respectively. Controls were obtained using primary antibodies pre-adsorbed with their respective immunogens, and also omitting the primary antibodies. Immunoblotting images were quantified using the Gel-Pro Analyzer version 3.1 software (Media Cybernetics, USA). Integrated optical densities (IOD) for the specific protein bands were determined, and the ratio IOD/ $\mu \mathrm{g}$ homogenate protein applied to the gel was calculated.

\section{Statistical analyses}

Repeated measures analysis of variance (ANOVA) was used to compare the hemodynamic patterns of response of the $P$ and $L$ groups, both over time (time-treatment interaction) and independent of time (overall group difference) for the dependent variables. One-way ANOVA was used to compare Western blot data among the $\mathrm{P}, \mathrm{L}$, and $\mathrm{C}$ groups, and the Tukey multiple comparison test was used as post hoc analysis. The Mann-Whitney rank sum test was used to compare the immunohistochemical scores. The consistency between two investigators scoring immunohistochemical results was analyzed using the weighed $\mathrm{k}$ coefficient that ranged from 0.7 to 0.85 , thus indicating good agreement. Data are reported as means $\pm S D$. $P<0.05$ was considered to be statistically significant.

\section{Results}

There were no statistically significant differences in weight gain or hemoglobin between the $P$ and $L$ groups at any time in room air or $12 \% \mathrm{O}_{2}$. There were no significant differences in $\mathrm{ABG}$ or acid-base values in room air/normoxia and hypoxia or in systemic hemodynamic responses (Psa, SVR, and CO) between the P and L groups. There was a statistically significant difference from normoxia to hypoxia in $\mathrm{PaO}_{2}$ values in both groups (Table 1). A significant attenu- 
Table 1. Effect of hypoxia and treatment with an angiotensin II type 1 blocker on newborn piglets.

\begin{tabular}{|c|c|c|c|c|}
\hline \multirow[t]{2}{*}{ Variables } & \multirow[t]{2}{*}{ Group } & \multirow[t]{2}{*}{ Normoxia } & \multicolumn{2}{|c|}{ Chronic hypoxia } \\
\hline & & & 2 days & 6 days \\
\hline \multirow[t]{2}{*}{$\mathrm{pH}$} & $P$ & $7.47 \pm 0.03$ & $7.51 \pm 0.02$ & $7.48 \pm 0.04$ \\
\hline & $\mathrm{L}$ & $7.41 \pm 0.05$ & $7.48 \pm 0.04$ & $7.50 \pm 0.06$ \\
\hline \multirow[t]{2}{*}{$\mathrm{PaCO}_{2}(\mathrm{mmHg})$} & $\mathrm{P}$ & $39 \pm 6$ & $30 \pm 2$ & $30 \pm 4$ \\
\hline & $\mathrm{L}$ & $42 \pm 5$ & $30 \pm 2$ & $31 \pm 4$ \\
\hline \multirow[t]{2}{*}{$\mathrm{PaO}_{2}(\mathrm{mmHg})$} & $\mathrm{P}$ & $94 \pm 8$ & $40 \pm 9^{*}$ & $42 \pm 7^{*}$ \\
\hline & $\mathrm{L}$ & $103 \pm 8$ & $47 \pm 9^{*}$ & $45 \pm 7^{*}$ \\
\hline \multirow[t]{2}{*}{$\mathrm{BE}(\mathrm{mM})$} & $\mathrm{P}$ & $5 \pm 4$ & $2 \pm 2$ & $1 \pm 5$ \\
\hline & $\mathrm{L}$ & $3 \pm 5$ & $1 \pm 3$ & $3 \pm 4$ \\
\hline \multirow[t]{2}{*}{ Psa (mmHg) } & $P$ & $71 \pm 6$ & $78 \pm 9$ & $79 \pm 16$ \\
\hline & $\mathrm{L}$ & $75 \pm 5$ & $68 \pm 6$ & $70 \pm 8$ \\
\hline \multirow[t]{2}{*}{$\operatorname{SVR}\left(\mathrm{mmHg} \cdot \mathrm{L}^{-1} \cdot \mathrm{min}^{-1} \cdot \mathrm{kg}^{-1}\right)$} & $\mathrm{P}$ & $254 \pm 26$ & $234 \pm 56$ & $284 \pm 89$ \\
\hline & $\mathrm{L}$ & $299 \pm 69$ & $239 \pm 31$ & $263 \pm 51$ \\
\hline \multirow[t]{2}{*}{$\mathrm{CO}\left(\mathrm{L} \cdot \mathrm{min}^{-1} \cdot \mathrm{kg}^{-1}\right)$} & $\mathrm{P}$ & $0.28 \pm 0.03$ & $0.32 \pm 0.04$ & $0.28 \pm 0.07$ \\
\hline & L & $0.24 \pm 0.04$ & $0.27 \pm 0.02$ & $0.25 \pm 0.04$ \\
\hline
\end{tabular}

Data are reported as means $\pm \mathrm{SD}$. BE $=$ base excess; Psa $=$ mean systemic arterial pressure; SVR = systemic vascular resistance; $\mathrm{CO}=$ cardiac output; $\mathrm{P}$ = placebo group $(N=6) ; L=L-158,809$ group $(N=7)$. There were no significant differences in arterial blood gas or acid-base values in room air/normoxia and hypoxia or in systemic hemodynamics and $\mathrm{CO}$ responses between groups. There was a statistically significant difference from normoxia to hypoxia in $\mathrm{PaO}_{2}$ values in both groups ( ${ }^{*} \mathrm{P}<0.05$, Mann-Whitney $\mathrm{U}$-test).
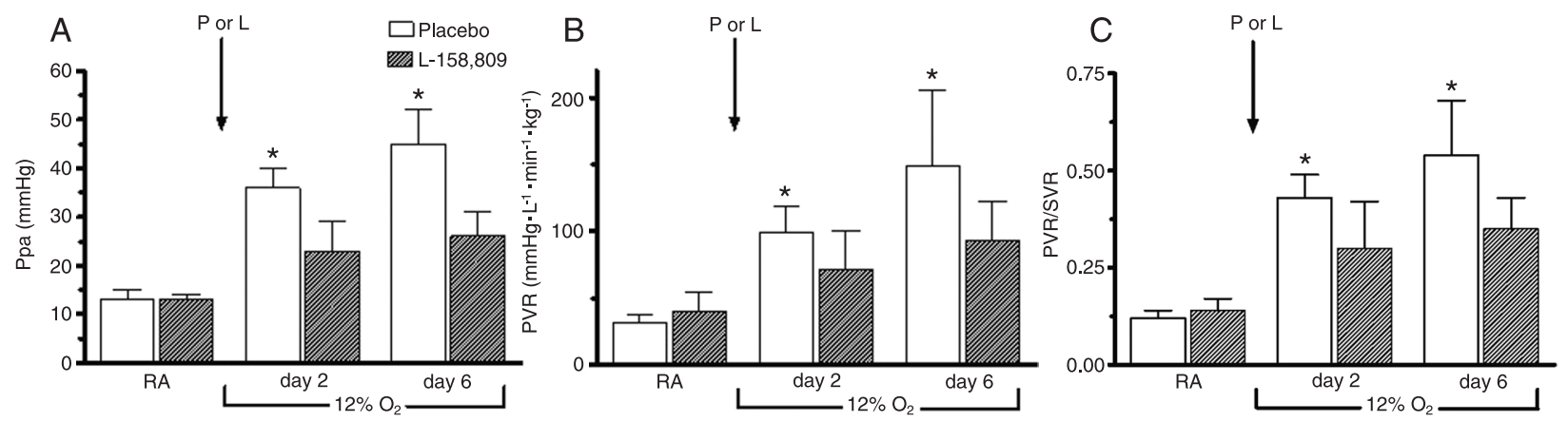

Figure 1. $A$, Pulmonary artery pressure (Ppa); $B$, pulmonary vascular resistance (PVR), and $C$, PVR/SVR ratio in normoxia and on the second and sixth days of hypoxia in the $P$ and $L$ groups. Pulmonary hypertension induced by chronic hypoxia was markedly attenuated after $\mathrm{AT}_{1}$ receptor blockade. SVR = systemic vascular resistance; $\mathrm{P}=$ placebo group; $\mathrm{L}=\mathrm{L}-158,809$ group; $\mathrm{RA}=$ room air. $\mathrm{A}$ significant decrease in the PVR/SVR ratio was observed during $A T_{1}$ receptor blockade. Bars represent the mean $\pm S D$ value. ${ }^{*} P<0.05$ for significant difference between the $P$ and $L$ groups (repeated measures ANOVA).

ation of Ppa $(P<0.0001)$ and PVR $(P<0.02)$, and a decrease in the PVR/SVR ratio were observed during chronic hypoxia after $A T_{1}$ receptor blockade (Figure 1), suggesting a selective action on the pulmonary circulation.

\section{Immunohistochemistry}

The endothelium of blood vessels with a diameter up to
$600 \mu \mathrm{m}$ exhibited a moderate (groups $\mathrm{L}$ and $\mathrm{P}$; Figure $2 \mathrm{~A}$ and $\mathrm{B}$, respectively) or strong (control; Figure $2 \mathrm{C}$ ) staining by anti-eNOS antibody. However, modal scores for eNOS staining were not significantly different among the three groups (Table 2).

The endothelium of the pulmonary arteries of the $L$ and $P$ groups was weakly stained (grade 1; Figure 2D,E) 

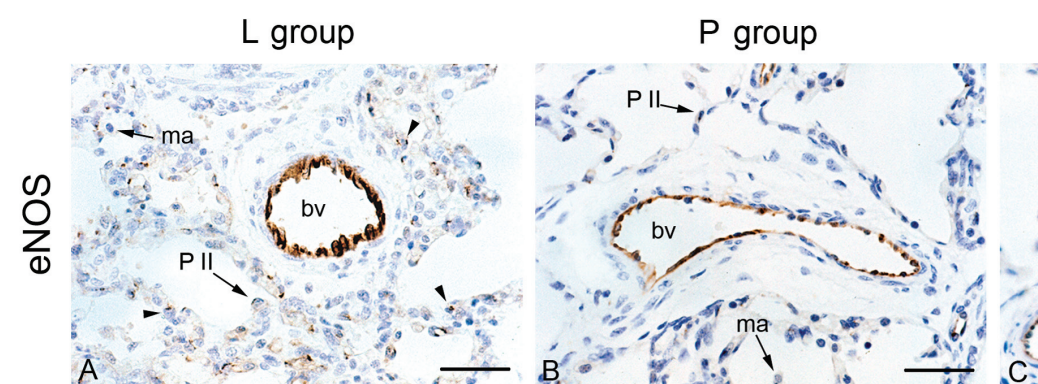

\section{C group}

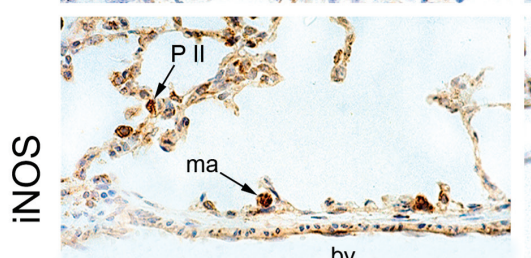

bv
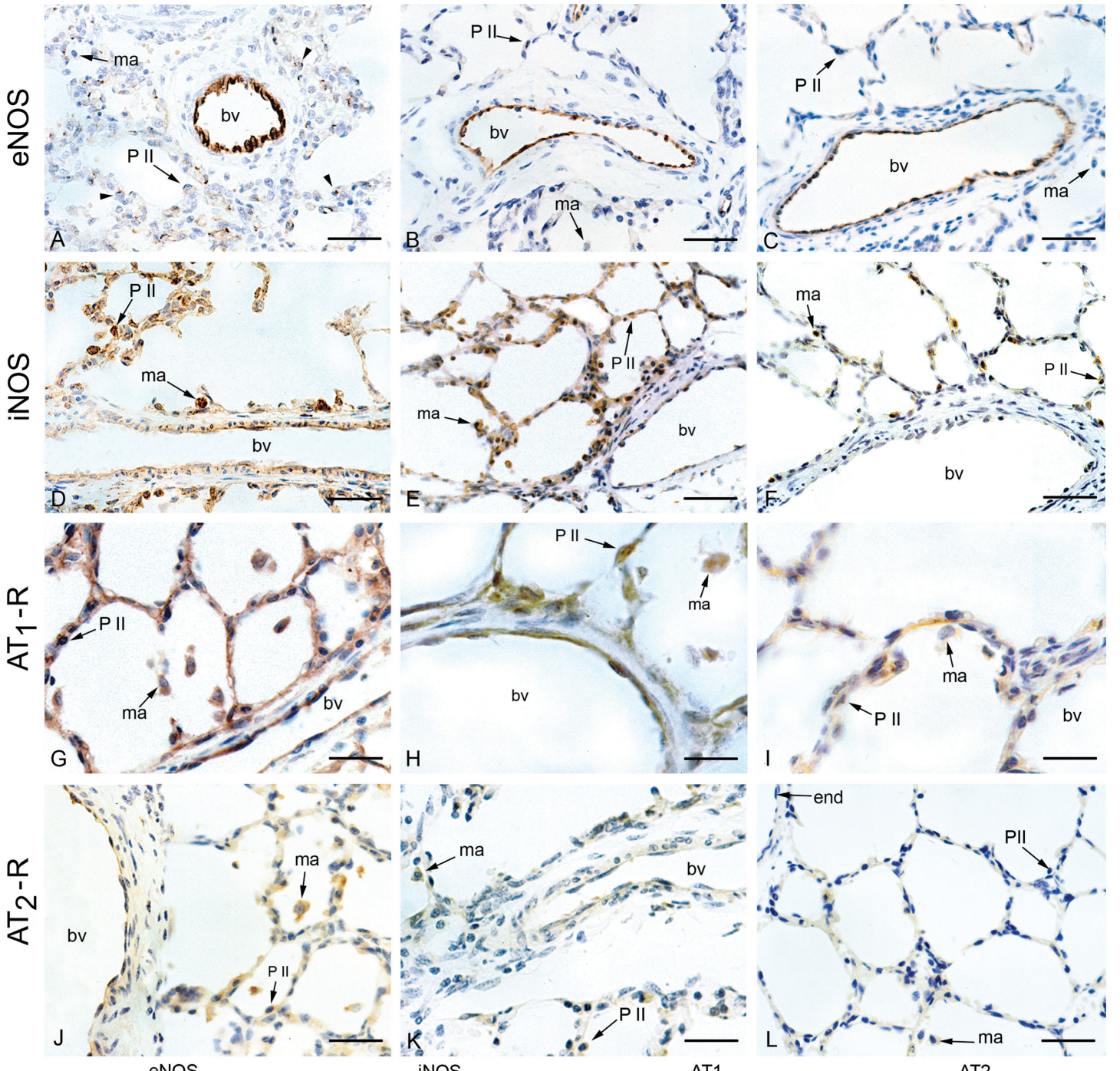

bv

iNOS
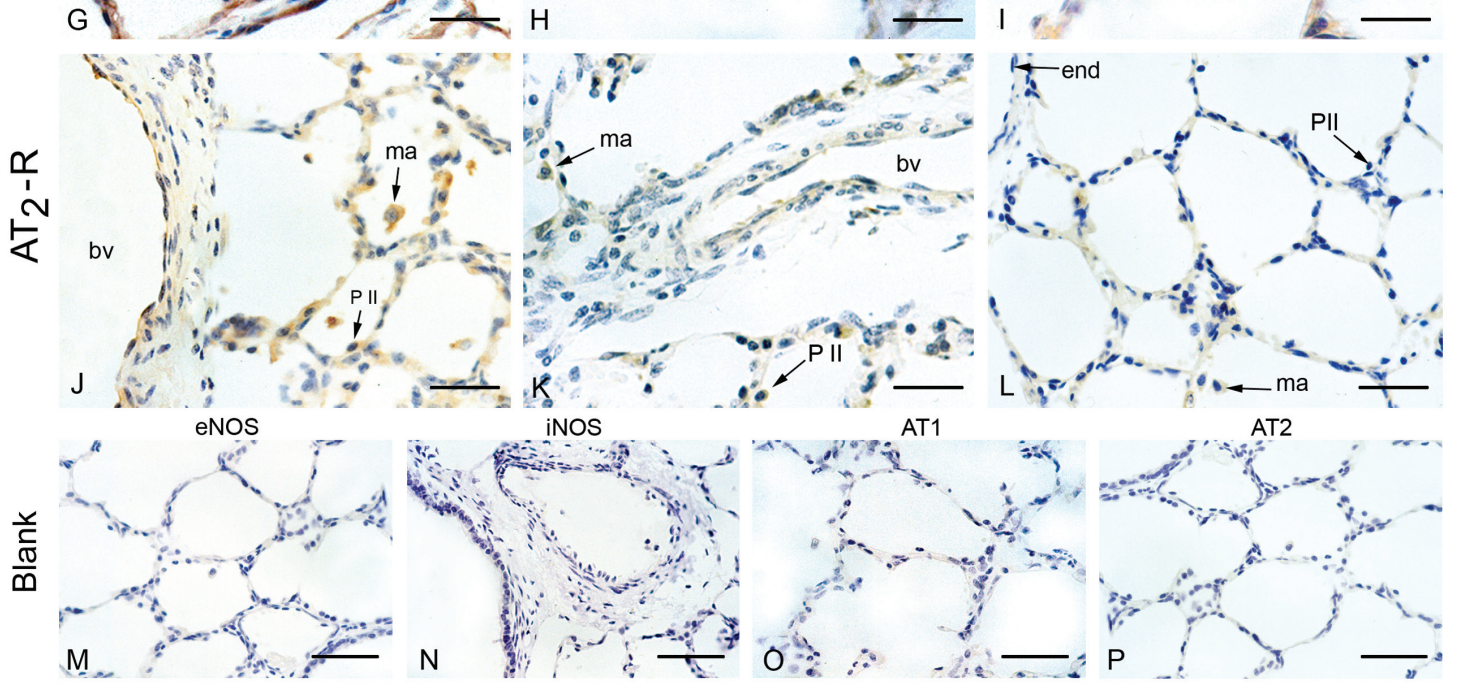

Figure 2. Immunohistochemical localization of eNOS, iNOS, $A T_{1}-R$ and $A T_{2}-R$ in the lungs of the hypoxic groups $L$ ( $L-158,809$-treated) and $\mathrm{P}$ (placebo) that were submitted to 6 days of hypoxia and of normoxic piglets (group $\mathrm{C}$, control). $A-C$, eNOS stained the endothelium of blood vessels (bv) in all groups; $D-F$, iNOS staining of the endothelium, alveolar and interstitial macrophages (ma) was observed in hypoxic ( $L$ and $P$ groups) but not in normoxic animals; $G-I, A T_{1}-R$ was expressed in the endothelium of all groups; macrophages and type II pneumocytes (P II) were moderately stained in the groups $L$ and $P$, and were weakly stained in normoxic (group $C$ ) animals; $J-L$, a weak $A T_{2}-R$ staining was observed in the endothelium (end), whereas macrophages in the $\mathrm{P}$ and $\mathrm{L}$ groups exhibited weak or moderate staining, respectively; $M-P$, immunohistochemistry controls for eNOS and iNOS were carried out omitting the respective primary antibodies (blank); controls for $A T_{1}-\mathrm{R}$ and $A T_{2}-\mathrm{R}$ were obtained by pre-adsorbing the primary antibodies with their respective peptide immunogens; none of the controls were stained, indicating that detection was specific. Bars $=4 \mu \mathrm{m}(\mathrm{A}-\mathrm{F}) ; 2 \mu \mathrm{m}(\mathrm{G}-\mathrm{L})$ and 10 $\mu \mathrm{m}(\mathrm{M}-\mathrm{P})$. eNOS = endothelial nitric oxide synthase; $\mathrm{iNOS}=$ inducible nitric oxide synthase, $A T_{1}-\mathrm{R}=A T_{1}$ receptor; $A T_{2}-\mathrm{R}$ $=\mathrm{AT}_{2}$ receptor. 
Table 2. Immunohistochemical quantification by modal scores of eNOS, iNOS, $A T_{1}-R$, and $A T_{2}-R$.

\begin{tabular}{|c|c|c|c|c|c|c|c|c|c|c|c|c|}
\hline \multirow[t]{2}{*}{ Structure } & \multicolumn{3}{|c|}{ eNOS } & \multicolumn{3}{|c|}{ iNOS } & \multicolumn{3}{|c|}{$\mathrm{AT}_{1}-\mathrm{R}$} & \multicolumn{3}{|c|}{$\mathrm{AT}_{2}-\mathrm{R}$} \\
\hline & C & $\mathrm{P}$ & $\mathrm{L}$ & C & $\mathrm{P}$ & $\mathrm{L}$ & C & $\mathrm{P}$ & $\mathrm{L}$ & $\mathrm{C}$ & $\mathrm{P}$ & L \\
\hline Endothelium & 3 & 2 & 2 & 0 & 1 & 1 & 1 & 2 & 2 & 1 & 1 & 1 \\
\hline Pneumo II & 0 & 0 & 1 & 2 & 2 & 2 & 1 & 2 & 2 & 0 & 1 & 1 \\
\hline Macrophages & 0 & 0 & 0 & 0 & $1^{*}$ & $2^{*}$ & 1 & 2 & 2 & 0 & $1^{* *}$ & $2^{* *}$ \\
\hline
\end{tabular}

$0=$ not detectable, $1=$ mild $/$ weak, 2 = moderate, and $3=$ strong staining. eNOS $=$ endothelial nitric oxide synthase; iNOS = inducible NOS; $\mathrm{AT}_{1}-\mathrm{R}=\mathrm{AT} \mathrm{T}_{1}$ receptor; $\mathrm{AT}_{2}-\mathrm{R}=\mathrm{AT} \mathrm{T}_{2}$ receptor; $\mathrm{C}=$ control group $(\mathrm{N}=5) ; \mathrm{P}=$ placebo group $(\mathrm{N}=6) ; \mathrm{L}=\mathrm{L}-158,809$ group $(N=7)$. There was a significant difference between the $P$ and $L$ groups for iNOS $\left({ }^{*} P<0.01\right)$ and $A T_{2}-R\left({ }^{* *} P<0.02\right)$ in macrophages (Mann-Whitney rank sum test).
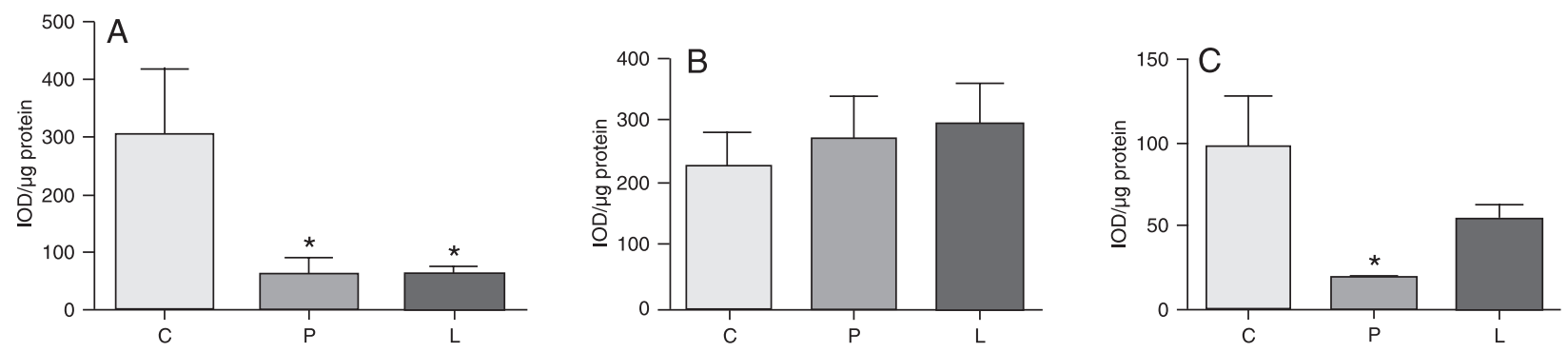

Figure 3. Western blot analysis of the expression of endothelial nitric oxide synthase (eNOS; Panel A), inducible nitric oxide synthase (iNOS; Panel B) and $A_{1}$ receptor $\left(A T_{1}-R ;\right.$ Panel $C$ ) in piglet lungs submitted (groups $L$ and $P$ ) or not (group $C$ ) to 6 days of hypoxia. Data are reported as integrated optical density (IOD) per $\mu$ g protein (mean $\pm S D$ ), expressed in arbitrary units. $C=$ control group; $P=$ placebo group; $\mathrm{L}=\mathrm{L}-158,809$ group. ${ }^{*} \mathrm{P}<0.01$ compared to group $\mathrm{C}$ (one-way ANOVA and Tukey multiple comparison as a post hoc test).

by anti-iNOS antibody, whereas that of the control group was essentially not stained (grade 0). Alveolar and interstitial macrophages were detected in lower numbers and showed grade 2 staining in the $L$ group (Figure 2D) and grade 1 staining in the $\mathrm{P}$ group (Figure 2E), and this difference in macrophage staining was significant $(P<0.01)$. The control group (Figure $2 \mathrm{~F}$ ) exhibited very few macrophages that stained grade 0 (Table 2).

$\mathrm{AT}_{1}-\mathrm{R}$ immunostaining was detected in the endothelium and alveolar interstitium of all groups, with no statistically significant differences among the three groups. Macrophages and type II pneumocytes were moderately stained in groups $L$ and $P$, and were weakly stained in the $C$ group (Figure 2G-I; Table 2).

A mild $A T_{2}-R$ immunoreactivity was detected in the alveolar septa (grade 1 ) in all sections of the $L$ group. Macrophages of the $P$ and $L$ groups exhibited weak (grade 1 ) or moderate (grade 2) staining, respectively (Figure 2J,K). The $P$ group significantly differed from the $L$ group $(P<0.02)$, where only half the sections showed a weak macrophage staining for $\mathrm{AT}_{2}-\mathrm{R}$ expression (grade 1 ), and a weak staining in the endothelium and alveolar septa (Figure $2 \mathrm{~K}$ ). The $\mathrm{C}$ group showed a very weak or absent expression of $A T_{2}-R$ (Figure 2L). Immunohistochemical blanks showed no stain- ing for any of the antibodies used (Figure 2M-P).

\section{Western blotting of eNOS, iNOS and $\mathrm{AT}_{1}$ receptors}

Hypoxia elicited a significant $(P<0.01)$ decrease of immunoreactive eNOS lung protein of both the $P$ and $L$ groups relative to the normoxia $C$ group levels, as measured by immunoblotting (Figure 3A). Expression of iNOS protein did not significantly differ among the $C, P$ and $L$ groups (Figure $3 B$ ). Although $A T_{1}-R$ expression in the $L$ group was numerically smaller than in the $C$ group (Figure $3 C$ ), the difference was not statistically significant. The $P$ group significantly differed from the $C$ group $(P<0.001)$, but not from the $L$ group. These data are consistent with the interpretation of a tendency to down-regulation of $A T_{1}-R$ in the $L$ group as compared to the normoxia $\mathrm{C}$ group.

\section{Discussion}

Pulmonary hypertension induced by chronic hypoxia in newborn piglets was markedly attenuated by L-158,809, a highly potent and selective nonpeptide $A T_{1}-\mathrm{R}$ blocker (19). The fact that the increase in the PVR/SVR ratio was significantly attenuated during chronic hypoxia in the $\mathrm{L}$ group suggests the occurrence of a selective pulmonary 
vasodilatation after $\mathrm{AT}_{1}-\mathrm{R}$ blockade.

The attenuation of the pulmonary hypertension of newborn piglets exposed to hypoxia for 6 days is consistent with previous studies examining the role of the RAS during the development of chronic hypoxic pulmonary hypertension. Adult rats were exposed to 7 or 14 days of hypoxia, showing attenuation of pulmonary hypertension after $A T_{1}-\mathrm{R}$ blockade $(6,20)$. In another study using adult rats exposed for 2-6 weeks to a $10 \%$ oxygen atmosphere in a normobaric chamber, olmesartan medoxomil (an $\mathrm{AT}_{1}-\mathrm{R}$ blocker) significantly reduced the induction of hypoxic cor pulmonale not only on echocardiographic observations but also in brain natriuretic peptide, transforming growth factor $\beta$ and endothelin gene expressions in molecular studies; systolic blood pressure was independent of olmesartan medoxomil (21). The same investigators reported that olmesartan still seems to block a potential positive feedback loop of the Ang II-AT 1 -R system, which may lead to attenuation of pro-inflammatory signals in the mouse lung, that are associated with hypoxic pulmonary hypertension (22). These observations were confirmed in adult humans when the RAS was not previously activated by dehydration or sodium depletion (23). In addition, we have demonstrated that pulmonary vasoconstriction induced by acute hypoxia in newborn piglets was significantly attenuated by the $\mathrm{AT}_{1}-\mathrm{R}$ blocker losartan (2).

It is important to consider possible mechanisms underlying pulmonary hypertension and the mechanisms related to the effects of the $A T_{1}-R$ antagonist, since hypoxic pulmonary hypertension was attenuated by $A T_{1}-R$ blockade in the present study. The association between the exposure of newborn piglets to chronic hypoxia and impairment of the endothelium-dependent vasodilatation ability related to the decreased eNOS expression has been very well demonstrated (10). It should be pointed out that eNOS expression did not return to control values after 6 days of AT 1 - $\mathrm{R}$ blockade.

Concerning other sources of NO production, iNOS protein expression was not significantly different among groups in the present study. However, there was a statistically significant difference in iNOS immunohistochemical expression in modal macrophage scores. Probably this difference was not detected in terms of protein expression because the Western blot data were assessed in the whole lung homogenate, and the iNOS expression was only different between the $P$ and $L$ groups at the level of macrophages.

Inducible NOS, in contrast to eNOS, has been primarily related to the immune function of macrophages. Inducible NOS is induced by a variety of stimuli such as cytokines, inflammatory factors, and hypoxia, which result in the release of much higher amounts of NO by very complex mechanisms involving different modulating factors such as hypoxia-induced factor 1 , interleukin 1- $\beta$ and Ang II (24-27). However, in agreement with the data of the present study, some studies have shown that iNOS is up-regulated in the pulmonary vasculature and in cardiac tissue in different animal models and in humans exposed to hypoxia, suggesting that hypoxia down-regulates eNOS activity and expression and up-regulates iNOS. This may represent an alternative adaptive mechanism counteracting the effects of hypoxia in the cardiovascular system. This is not necessarily a favorable adaptive mechanism because excess iNOS can induce the production of reactive oxygen species such as nitrotyrosine, facilitating tissue damage and hypotension (26,28-30).

Concerning $A T_{1}-R$ protein expression, the present study did not show the transient up-regulation observed in rodents (6). On the contrary, only a down-regulation was demonstrable in the placebo group compared to normoxic controls. This could be related to species differences and the duration of hypoxia to which the animals were submitted.

Analyzing the mechanisms that could explain the effects of $A T_{1}-R$ blockade, several studies have shown that $\mathrm{AT}_{1}-\mathrm{R}$ blockade acts through increased NO production via the $A T_{2}-R$, demonstrating the relationship between the RAS and nitrergic systems in different models, including the pulmonary circulation, causing vasodilatation $(8,9,31$ 33). Furthermore, increased Ang II can be converted to angiotensin-(1-7) by the action of angiotensin-converting enzyme-2. Angiotensin-(1-7) acts through the Mas receptors $(34,35)$ resulting in pulmonary vasodilatation and thus can counteract the action of Ang II, increasing the release of $\mathrm{NO}(36,37)$.

The mild immunoreactive expression of $A T_{2}-R$ observed here in the $P$ and $L$ groups, significantly more intense in the L group, is unexpected during the neonatal period $(6,38,39)$ and may represent a compensatory mechanism due to hypoxic pulmonary hypertension, perhaps enhanced by the $A T_{1}-R$ blockade in the $L$ group.

In conclusion, pulmonary hypertension induced by chronic hypoxia was partially attenuated by $A T_{1}-\mathrm{R}$ blockade in newborn piglets. The chronic hypoxic pulmonary hypertension could be explained by down-regulated eNOS expression. We suggest that $A T_{1}-\mathrm{R}$ blockade attenuated the hypoxic pulmonary hypertension acting through $A T_{2}-R$ and/or Mas receptors and the nitrergic system in the lungs of hypoxemic newborn piglets.

\section{Acknowledgments}

We wish to thank Silvia Helena Henriques Camelo and Carlos Devia for help with data collection, and Adriana Pelegrini-da-Silva for the immunohistochemical studies. Research supported by the University of Miami: Project New Born. Merck Research Laboratories provided L-158,809 in powder form. J.S. Camelo Jr. received a scholarship from FAPESP. 


\section{References}

1. Stenmark KR, Fagan KA, Frid MG. Hypoxia-induced pulmonary vascular remodeling: cellular and molecular mechanisms. Circ Res 2006; 99: 675-691.

2. Camelo JS Jr, Hehre D, Devia C, Camelo SH, Bancalari E, Suguihara $\mathrm{C}$. The role of angiotensin II receptor-1 blockade in the hypoxic pulmonary vasoconstriction response in newborn piglets. Neonatology 2008; 93: 263-268.

3. Marshall RP, McAnulty RJ, Laurent GJ. Angiotensin II is mitogenic for human lung fibroblasts via activation of the type 1 receptor. Am J Respir Crit Care Med 2000; 161: 19992004.

4. Jeffery TK, Wanstall JC. Pulmonary vascular remodeling: a target for therapeutic intervention in pulmonary hypertension. Pharmacol Ther 2001; 92: 1-20.

5. Solari V, Puri P. Genetic polymorphisms of angiotensin system genes in congenital diaphragmatic hernia associated with persistent pulmonary hypertension. $J$ Pediatr Surg 2004; 39: 302-306

6. Morrell NW, Morris KG, Stenmark KR. Role of angiotensinconverting enzyme and angiotensin II in development of hypoxic pulmonary hypertension. Am J Physiol 1995; 269: H1186-H1194.

7. Chassagne C, Eddahibi S, Adamy C, Rideau D, Marotte F, Dubois-Rande JL, et al. Modulation of angiotensin II receptor expression during development and regression of hypoxic pulmonary hypertension. Am J Respir Cell Mol Biol 2000; 22: 323-332.

8. Kalinowski L, Matys T, Chabielska E, Buczko W, Malinski T. Angiotensin II AT1 receptor antagonists inhibit platelet adhesion and aggregation by nitric oxide release. Hypertension 2002; 40: 521-527.

9. Ye S, Zhong H, Duong VN, Campese VM. Losartan reduces central and peripheral sympathetic nerve activity in a rat model of neurogenic hypertension. Hypertension 2002; 39: 1101-1106.

10. Fike CD, Aschner JL, Zhang Y, Kaplowitz MR. Impaired NO signaling in small pulmonary arteries of chronically hypoxic newborn piglets. Am J Physiol Lung Cell Mol Physiol 2004; 286: L1244-L1254.

11. Lapointe A, Barrington KJ. Pulmonary hypertension and the asphyxiated newborn. J Pediatr 2011; 158: e19-e24.

12. Huckle WR, Drag MD, Acker WR, Powers M, McFall RC, Holder DJ, et al. Effects of subtype-selective and balanced angiotensin II receptor antagonists in a porcine coronary artery model of vascular restenosis. Circulation 1996; 93: 1009-1019.

13. Martins AR, Zanella CA, Zucchi FC, Dombroski TC, Costa ET, Guethe LM, et al. Immunolocalization of nitric oxide synthase isoforms in human archival and rat tissues, and cultured cells. J Neurosci Methods 2011; 198: 16-22.

14. Martins AR, Dias MM, Vasconcelos TM, Caldo H, Costa MC, Chimelli L, et al. Microwave-stimulated recovery of myosin$\mathrm{V}$ immunoreactivity from formalin-fixed, paraffin-embedded human CNS. J Neurosci Methods 1999; 92: 25-29.

15. Mirza MH, Oliver JL, Seahorn TL, Hosgood G, Moore RM. Detection and comparison of nitric oxide in clinically normal horses and those with naturally acquired small intestinal strangulation obstruction. Can J Vet Res 1999; 63: 230240.
16. Tilelli CQ, Martins AR, Larson RE, Garcia-Cairasco N. Immunohistochemical localization of myosin Va in the adult rat brain. Neuroscience 2003; 121: 573-586.

17. Laemmli UK, Favre M. Maturation of the head of bacteriophage T4. I. DNA packaging events. J Mol Biol 1973; 80: 575-599.

18. Towbin H, Staehelin T, Gordon J. Electrophoretic transfer of proteins from polyacrylamide gels to nitrocellulose sheets: procedure and some applications. Proc Natl Acad Sci U S A 1979; 76: 4350-4354.

19. Fulton GJ, Davies MG, Barber L, Svendsen E, Hagen PO. Localized versus systemic angiotensin II receptor inhibition of intimal hyperplasia in experimental vein grafts by the specific angiotensin II receptor inhibitor L158,809. Surgery 1998; 123: 218-227.

20. Zhao L, al-Tubuly R, Sebkhi A, Owji AA, Nunez DJ, Wilkins $M R$. Angiotensin II receptor expression and inhibition in the chronically hypoxic rat lung. Br J Pharmacol 1996; 119: 1217-1222.

21. Nakamoto $T$, Harasawa $H$, Akimoto $K$, Hirata $H$, Kaneko $H$, Kaneko $\mathrm{N}$, et al. Effects of olmesartan medoxomil as an angiotensin II-receptor blocker in chronic hypoxic rats. Eur J Pharmacol 2005; 528: 43-51.

22. Tanabe $\mathrm{Y}$, Morikawa $\mathrm{Y}$, Kato $\mathrm{T}$, Kanai $\mathrm{S}$, Watakabe $\mathrm{T}$, Nishijima A, et al. Effects of olmesartan, an AT1 receptor antagonist, on hypoxia-induced activation of ERK $1 / 2$ and pro-inflammatory signals in the mouse lung. Naunyn Schmiedebergs Arch Pharmacol 2006; 374: 235-248.

23. Cargill RI, Lipworth BJ. Lisinopril attenuates acute hypoxic pulmonary vasoconstriction in humans. Chest 1996; 109: 424-429.

24. Forstermann U, Sessa WC. Nitric oxide synthases: regulation and function. Eur Heart $J 2011$ [ahead of print]

25. Angele MK, Schwacha MG, Smail N, Catania RA, Ayala A, Cioffi WG, et al. Hypoxemia in the absence of blood loss upregulates iNOS expression and activity in macrophages. Am J Physiol 1999; 276: C285-C290.

26. Strunk V, Hahnenkamp K, Schneuing M, Fischer LG, Rich GF. Selective iNOS inhibition prevents hypotension in septic rats while preserving endothelium-dependent vasodilation. Anesth Analg 2001; 92: 681-687.

27. Jiang B, Xu S, Hou X, Pimentel DR, Cohen RA. Angiotensin Il differentially regulates interleukin-1-beta-inducible NO synthase (iNOS) and vascular cell adhesion molecule-1 (VCAM-1) expression: role of p38 MAPK. J Biol Chem 2004; 279: 20363-20368.

28. Palmer LA, Semenza GL, Stoler MH, Johns RA. Hypoxia induces type II NOS gene expression in pulmonary artery endothelial cells via HIF-1. Am J Physiol 1998; 274: L212L219.

29. Aikio O, Vuopala K, Pokela ML, Andersson S, Hallman M. Nitrotyrosine and NO synthases in infants with respiratory failure: influence of inhaled NO. Pediatr Pulmonol 2003; 35: 8-16.

30. Shehata SM, Sharma HS, Mooi WJ, Tibboel D. Pulmonary hypertension in human newborns with congenital diaphragmatic hernia is associated with decreased vascular expression of nitric-oxide synthase. Cell Biochem Biophys 2006; 44: 147-155. 
31. Abadir PM, Carey RM, Siragy HM. Angiotensin AT2 receptors directly stimulate renal nitric oxide in bradykinin B2receptor-null mice. Hypertension 2003; 42: 600-604.

32. Thai H, Wollmuth J, Goldman S, Gaballa M. Angiotensin subtype 1 receptor (AT1) blockade improves vasorelaxation in heart failure by up-regulation of endothelial nitric-oxide synthase via activation of the AT2 receptor. J Pharmacol Exp Ther 2003; 307: 1171-1178.

33. Olson S, Oeckler R, Li X, Du L, Traganos F, Zhao X, et al. Angiotensin II stimulates nitric oxide production in pulmonary artery endothelium via the type 2 receptor. Am J Physiol Lung Cell Mol Physiol 2004; 287: L559-L568.

34. Santos RA, Simoes e Silva AC, Maric C, Silva DM, Machado RP, de Buhr I, et al. Angiotensin-(1-7) is an endogenous ligand for the $\mathrm{G}$ protein-coupled receptor Mas. Proc Natl Acad Sci U S A 2003; 100: 8258-8263.

35. Santos RA, Ferreira AJ, Simoes e Silva AC. Recent advances in the angiotensin-converting enzyme 2-angiotensin(1-7)Mas axis. Exp Physiol 2008; 93: 519-527.

36. Kuba K, Imai Y, Ohto-Nakanishi T, Penninger JM. Trilogy of ACE2: a peptidase in the renin-angiotensin system, a SARS receptor, and a partner for amino acid transporters. Pharmacol Ther 2010; 128: 119-128.

37. Shenoy V, Qi Y, Katovich MJ, Raizada MK. ACE2, a promising therapeutic target for pulmonary hypertension. Curr Opin Pharmacol 2011; 11: 150-155.

38. Treml B, Neu N, Kleinsasser A, Gritsch C, Finsterwalder T, Geiger R, et al. Recombinant angiotensin-converting enzyme 2 improves pulmonary blood flow and oxygenation in lipopolysaccharide-induced lung injury in piglets. Crit Care Med 2010; 38: 596-601.

39. Cox BE, Liu XT, Fluharty SJ, Rosenfeld CR. Vessel-specific regulation of angiotensin II receptor subtypes during ovine development. Pediatr Res 2005; 57: 124-132. 